\title{
Variation in herbivory by Yponomeuta mahalebella on its only host plant Prunus mahaleb along an elevational gradient
}

\author{
C O N C H I T A A L O N S O Estación Biológica Doñana, C.S.I.C., Sevilla, Spain
}

\begin{abstract}
The effect of natural variation in abiotic conditions on the herbivory interaction between Prunur mahaleb (Rosaceae) and its monophagous folivore, larvae of Yponomeuta mahalebella (Lepidoptera, Yponomeutidae), was analysed for 2 consecutive years along an elevational gradient in Sierra de Cazorla, south-east Spain.

2. There was a negative correlation between site elevation and mean population herbivory level measured at the end of the growing period of $\mathrm{Y}$. mahalebella. Mortality during larval development was higher at higher elevation sites, and mean adult body mass was higher in lower elevation populations.

3. Variation in temperatures recorded during the larval growth period at different altitudes was the only study factor related to abundance of $\mathrm{Y}$. mahalebella larvae; neither differences in parasitisation rates nor plant features covaried significantly with herbivore abundance.

4. These results support the existence of geographical variation in plant-animal interactions in relation to environmental heterogeneity.
\end{abstract}

Key words. Elevational gradient, herbivory, Lepidoptera, natural enemies, plantinsect interaction, temperature, Yponomeutidae.

\section{Introduction}

Thompson's (1994) review of plant-animal interactions pointed out that these interspecific relationships can be modified by environmental conditions (e.g. Janzen, 1983; Dudt \& Shure, 1994; Herrera, 1993a,b and references therein; Louda \& Rodman, 1996). Studies of plant-animal interactions along natural abiotic gradients, e.g. latitudinal and altitudinal (McCoy, 1990; Stevens, 1992; Begon et al., 1996; Gaston et al., 1998), can help to evaluate the role of environmental factors in such relationships. Such studies are, however, scarce (e.g. Koptur, 1983; Hill \& Hodkinson, 1992), and conducted mainly in extreme climates, such as the Arctic, where abiotic factors are limiting for most species (Strathdee \& Bale, 1998). More general conclusions may be obtained by studying altitudinal gradients in less extreme conditions.

This study focuses on the highly specific relationship between the Saint Lucie's Cherry (Prunur mahaleb L., Rosaceae) and the small ermine moth (Yponomeuta mahalebella Latr., Lepidoptera: Yponomeutidae), within the altitu-

Correspondence: Conchita Alonso, Section of Ecology, Department of Biology, University of Turku, FIN-20014, Turku, Finland. E-mail: conalo@utu.fi dinal range distribution of $\mathrm{P}$. mahaleb at Sierra de Cazorla, Jaén province, south-east Spain $\left(37^{\circ} 39^{\prime} \mathrm{N}, 2^{\circ} 34^{\prime} \mathrm{W}\right)$. Prunur mahaleb is a small deciduous tree (2-8 $\mathrm{m}$ tall) of central and southern Europe that, within the Sierra de Cazorla, normally grows in small groups of less than 10 individuals, with a few scattered larger populations. Leaf flush begins in mid-April and development continues to the end of May. There is an approximately 10-day delay in flushing between populations at different elevations within the range considered in this study (C. Alonso, unpublished). The leaves of $P$. mahaleb contain coumarins and hydroxicoumarins (Fung \& Herrebout, 1987) that may play a feeding-deterrent role for many insects.

In late summer, females of Y. mahalebella deposit egg masses around the stems of P. mahaleb (Kooi, 1990). Eggs hatch before hibernation and first-instar larvae remain inside the batch shelter until the following spring. Caterpillars first become active in early April at lower sites and development continues until late June. From the second instar on, larvae, which are monophagous on $P$. mahaleb leaves, spin a conspicuous silk tent and feed gregariously on leaves therein. When food within the tent becomes limiting, caterpillars extend the tent along the same branch. The cylindrical tents can be measured easily in the field. 
The work reported here aimed to investigate which factors affect the study plant-herbivore system and particularly whether abiotic factors may be relevant for herbivory interactions in a temperate area. Patterns of covariation between air temperature, herbivory level, and herbivore performance were studied over 2 consecutive years in six $P$. mahaleb populations located at different elevations in the study area. Variations in the impact of natural enemies and plant features were also considered as alternative explanations to differences in herbivory along the study abiotic gradient. The specific questions addressed were: (1) How are Y. mahalebella larvae distributed among $P$. mahaleb populations? (2) Is their abundance related to site elevation? (3) Can natural variation in temperature, plant features, or natural-enemy populations explain the observed pattern?

\section{Methods}

Six P. mahaleb populations with altitudes ranging from 1300 to $1700 \mathrm{~m}$ (Table 1), and distances between sites varying from 2 to $8 \mathrm{~km}$, were selected in the southern part of Sierra de Cazorla Natural Park, a 214000 ha protected area in south-east Spain (Fig. 1). The elevation of study populations was determined directly by using an altimeter; however, because the exact elevation for all $P$. mahaleb populations in the area was not available, altitudinal distribution of $P$. mahaleb (Fig. 2) was obtained by cartographic analysis, using a 1:30000 scale map and detailed distribution information (Fig. 1; C. M. Herrera and P. Jordano, unpublished). A map of the area was reticulated and the average elevation for every $1-\mathrm{km}^{2}$ area where P. mahaleb was present $(n=127$, Fig. 1$)$ was calculated as the mean of their minimum and maximum elevations. An altitudinal profile of the southern half of the park where P. mahaleb is mainly located (Fig. 1) was drawn using the same method (i.e. calculating the mean of minimum and maximum elevation per $1 \mathrm{~km}^{2}$ ), and choosing a similar number of squares randomly $(n=124)$. This random sample represented $10 \%$ of the study area. This procedure indicated that $P$. mahaleb distribution in the area ranges from 900 to $1900 \mathrm{~m}$, with $30 \%$ of locations between 1400 and $1630 \mathrm{~m}$, and the largest $\mathrm{P}$. mahaleb populations located mainly between 1300 and $1800 \mathrm{~m}$ (Fig. 2).

Observations were carried out during the period in which $Y$. mahalebella larvae develop, from April to June, in 1994 and 1993. All P. mahaleb trees at each study population were marked initially in 1994 (see Table 1), except at the Torcal del Cerecino and Nava las Correhuelas sites, where only a subsample was marked owing to the large number of individuals present. At the same time, a minimum-maximum thermometer was attached to the shaded trunk of one tree at each population, and minimum and maximum weekly temperatures were recorded over the study period (Table 1). Mean weekly temperature was computed as (maximum + minimum)/2.

Marked trees were examined weekly and all Y. mahalebella tents found were marked with numbered, coloured tape. In 1994, numbers of $Y$. mahalebella larvae within tents were counted on each sampling date.

At the end of the season, total lengths of silk tents spun by $Y$. mahalebella larvae were estimated for each tree. The length of all individual tents in the tree, both with and without larvae inside, was summed. The incidence of $Y$. mahalebella at each site was calculated as the mean number of tents and mean tent length per tree.

Finally, to evaluate differences in herbivore fitness among populations, all tents holding live larvae were collected between 21 and 24 June 1994, and 18 and 20 June 1993, by clipping the branch portion they occupied. Branches were placed in polythene bags and kept at room temperature until emergence of moths or parasitoids. Moths were killed, sexed, dried at room temperature, and weighed. Parasitoid incidence was evaluated in collected samples as the proportion of parasitised individuals per tent. Although there are some methodological problems with estimation of parasitoid incidence from field collections (Van Driesche et al., 1991), it is unlikely that parasitised larvae changed behaviour, because this has not been reported for the same parasitoid species in other Yponomeuta sp. (Dijkerman etal., 1986; Kuhlman, 1993). Parasitism rate data should be therefore treated with caution, but they were suitable for comparisons among populations.

Table 1. Abiotic conditions of studied populations: elevation, and maximum, minimum, and mean weekly temperatures recorded during the 10week study period. Note that the differences among populations in elevation are not of the same magnitude, with two low, two intermediate, and two high elevation sites. $n=$ number of marked trees. Mean temperature was calculated as (maximum + minimum) $/ 2$.

\begin{tabular}{|c|c|c|c|c|c|c|c|c|}
\hline \multirow[b]{3}{*}{ Population } & \multirow[b]{3}{*}{ Elevation (m) } & \multirow[b]{3}{*}{$\mathrm{n}$} & \multicolumn{6}{|c|}{ Temperature $\left({ }^{\circ} \mathrm{C}\right)$} \\
\hline & & & \multicolumn{2}{|c|}{ Maximum } & \multicolumn{2}{|c|}{ Minimum } & \multicolumn{2}{|l|}{ Mean } \\
\hline & & & 1994 & 1993 & 1994 & 1993 & 1994 & 1993 \\
\hline Roblehondo & 1300 & 6 & 33 & 32 & -4 & -1.3 & 13.3 & 14.1 \\
\hline Poyo Manquillo & 1330 & 28 & 32.3 & 39 & 1 & -10 & 16.2 & 14.3 \\
\hline Torcal del Cerecino & 1330 & 20 & 29 & 36 & -3 & -8 & 13.8 & 14.1 \\
\hline Cañada la Medianega & 1360 & 21 & 27 & 23 & 1 & -2 & 13.9 & 11.4 \\
\hline Nava las Correhuelas & 1613 & 21 & 30 & 36 & -8 & -4 & 12.1 & 13.1 \\
\hline Cabeza del Tejo & 1640 & 26 & 29 & 36 & -9 & -11 & 12.7 & 13.1 \\
\hline
\end{tabular}




\section{Ertimation of herbivory}

Length of $\mathrm{Y}$. mahalebella tents was used as an estimate of herbivore consumption and abundance. To test the accuracy of this measurement, length of the tent, the number of caterpillars (herbivore load), and the number of leaves consumed (herbivory level) within it, were recorded for 100 tents collected in late June 1994. The relationship between number of larvae and length of the tent was also studied experimentally. On 2 June 1993, five tents were collected from an unmarked tree. Caterpillars from each tent were taken out of the tent and divided in three groups each with double the number of larvae of the previous group (e.g. 8-16-32). Fifteen branches from another

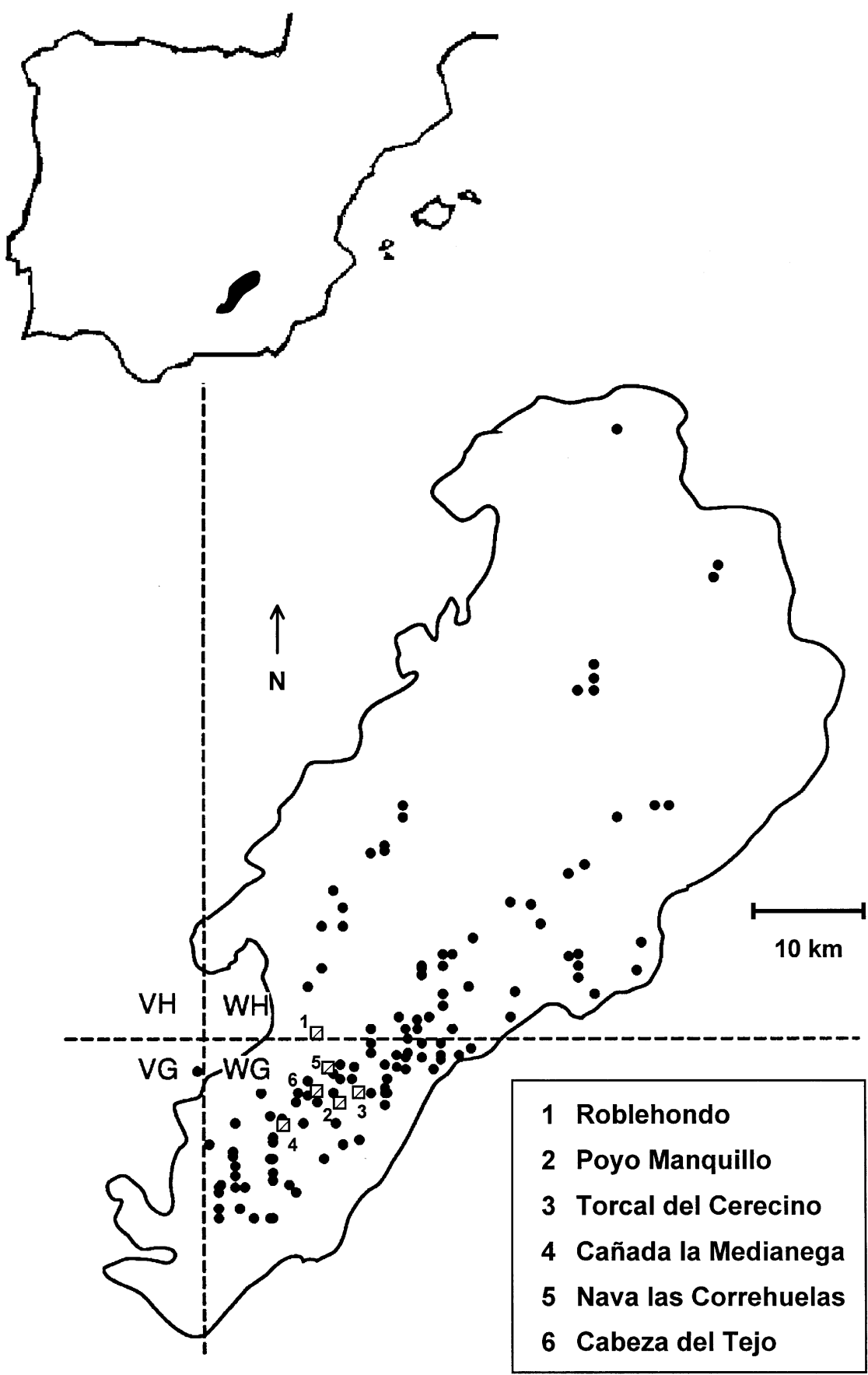

Fig. 1. Map of the study area showing the location of Sierra de Cazorla Natural Park, the distribution of P. mahaleb populations within it (dots), and the study sites (dashed squares). 


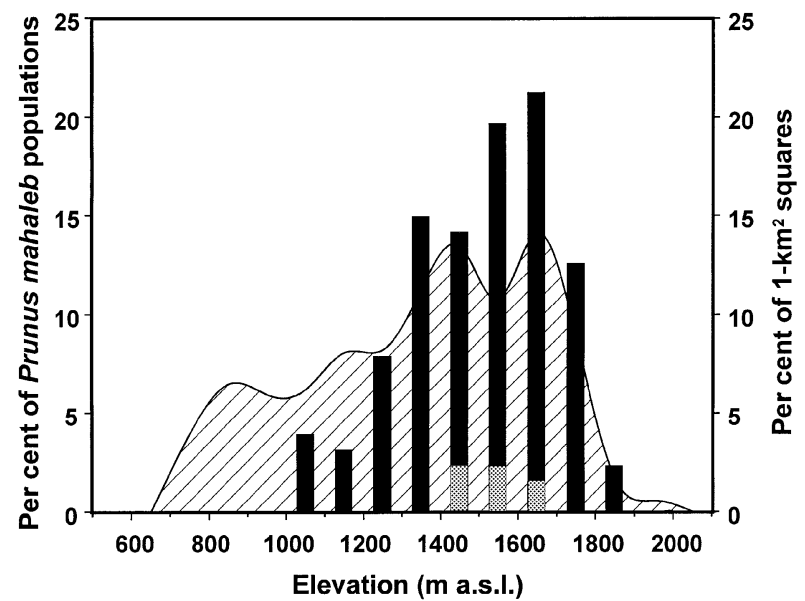

Fig. 2. Altitudinal distribution of $P$. mahaleb in the Sierra de Cazorla Natural Park. Black bars represent the percentage of $P$. mahaleb populations $(n=127)$ at different altitudes, with grey areas showing populations with $>10$ individuals. Dashed figure represents the percentage of land area at different altitudes, estimated from a random sample of $1-\mathrm{km}^{2}$ squares $(n=124)$ within the area (see Methods).

unmarked tree, each $=23 \mathrm{~cm}$ long, were cut and put into clip vials. Each group of caterpillars was put onto a branch portion and covered with transparent plastic bags to prevent escape. Branches were kept at room temperature, and the length of tents was measured after 3 days.

Size of the trees did not affect the estimates at tree level because larvae were never constrained by scarcity of free space within the study individuals.

\section{Data analyrir}

Differences in herbivory level among populations were evaluated using the nonparametric Kruskal-Wallis test, because neither the number of tents nor the total tent length per tree was distributed normally.

The relationships between tent length and both herbivory level and herbivore load were analysed by robust regression using the least median squared method within the PROGRESS program (Rousseeuw \& Leroy, 1987).

When there was an ordered prediction about differences among populations, isotonic regression was used (Gaines \& Rice, 1990).

Finally, tents were used as sample units to evaluate differences in herbivore performance among populations. Caterpillars growing within the same tent were not independent, probably belonging to the same brood, hatching at the same place, and growing in the same micro-environment, and thus were not statistically independent. The percentage of collected larvae reaching the adult stage was used to estimate survival, and adult body mass was used as an estimate of potential fecundity.
All analyses, except those stated above, were conducted using the SAS package (SAS Institute, 1996). Means are presented ! 1 SD.

\section{Results}

\section{Ertimation of herbivory}

Length of the tent in centimetres $(X)$ was related directly to the number of eaten leaves within the tent $(Y=1.8 \mathrm{X})$; the relationship was highly significant $(F=242.7$, d.f. $=1,98$, $P<0.001)$ and the regression explained a high percentage of variance $\left(R^{2}=0.92\right)$. Tent length $(X)$ was also related significantly to the number of caterpillars present at the end of the growing season $(Y=1.23+0.21 X ; F=40.8$, d.f. $=1,97$, $P<0.001$ ), however this model explained a lower percentage of variance $\left(R^{2}=0.26\right)$. For this reason, the relationship was also studied using a manipulative experiment where the number of caterpillars present was the only factor related significantly to the length of the tent after 3 days $(F=41.6$, d.f. $=1,3, P=0.001)$. Number of larvae explained a high percentage of variance in tent length $\left(R^{2}=0.83\right)$ in a model including also origin of the larvae and origin $\times$ number interaction.

At tree level, the total tent length was correlated significantly with the number of tents $\left[r_{s}(1994)=0.88, n=122\right.$, $\left.\mathrm{P}<0.001 ; \mathrm{r}_{\mathrm{s}}(1993)=0.98, \mathrm{n}=122, \mathrm{P}<0.001\right]$.

\section{Among-populationr variation in air temperature}

Maximum, minimum, and mean weekly temperatures recorded between mid-April and late-June did not differ significantly from 1994 to 1993 (d.f. $=1,109, P=N S$, for three separate ANOVAS; Table 1 ). Both maximum and minimum temperatures differed significantly among sites [F (maximum) $=3.1, \quad$ d.f. $=3,103, \quad P<0.03 ; \quad F \quad$ (minimum) $=3.2$, d.f. $=3,103, P<0.03$ ]. Maximum temperatures at the Cañada la Medianega site were significantly lower than at the other study sites, and minimum temperatures were significantly lower at Nava las Correhuelas than at the other sites. Mean temperatures were higher at the two low elevation sites than at the highest elevations (Table 1), but differences among sites in mean temperature were not statistically significant $(F=2.03$, d.f. $=3,103, P=N S$ ).

\section{Differenser in herbivory among populationr}

Study populations differed significantly in herbivory level $\left[\mathrm{z}^{2}\right.$ $(1994)=40.83$, d.f. $=3, P<0.001 ; z^{2} \quad(1993)=46.11$, d.f. $=3$, $\mathrm{P}<0.001$, Kruskal-Wallis tests]. Although overall herbivory was higher in 1994, differences among populations were consistent in both study seasons $\left(r_{s}=0.94, n=6, P<0.01\right.$; Fig. 3).

In 1994, herbivory at the population level was correlated negatively with site altitude $\left(r_{s}=-0.83, n=6, P<0.03\right)$ and positively with mean temperature recorded during the study 


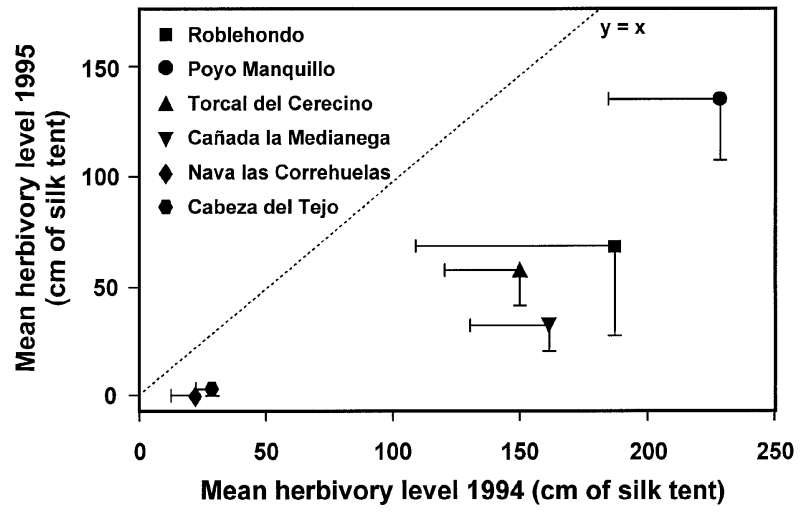

Fig. 3. Mean population herbivory level observed in the six $P$. mahaleb study populations in 1994 and 1993. Symbols represent mean values, bars $=-\mathrm{SEM}$, and the dotted line represents equality between years. Populations are ordered by altitude from lowest (Roblehondo) to highest (Cabeza del Tejo) elevation.

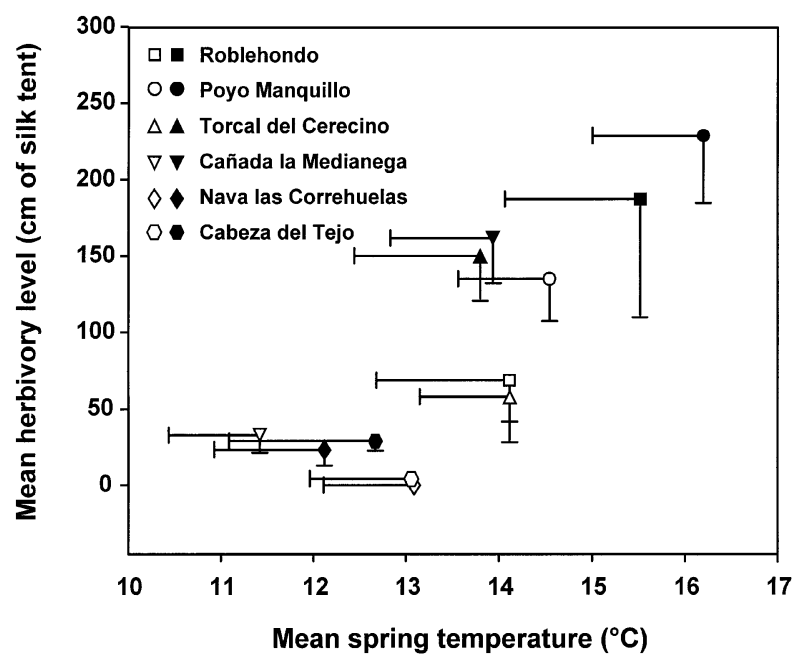

Fig. 4. Relationship between mean population herbivory level and mean temperature recorded during the 10-week study period (AprilJune) of $Y$. mahalebella larval development. Symbols represent mean values, and bars $=-S E M$. Different symbols identify study populations, with black symbols representing 1994 data and white symbols representing 1993 data. Populations are ordered by altitude from lowest (Roblehondo) to highest (Cabeza del Tejo) elevation.

season $\left(r_{s}=1, n=6, \quad P<0.01 ;\right.$ Fig. 4). This pattern was supported by the 1993 results (isotonic regression: $E^{2}=0.273, n=6, P<0.001$ ), where mean population herbivory increased steadily with mean population temperature.

Conrequenser for herbivorer growing within different tree populationr

Phenology. Date of Y. mahalebella tent appearance was correlated with site altitude (Fig. 3). Tents appeared earlier in

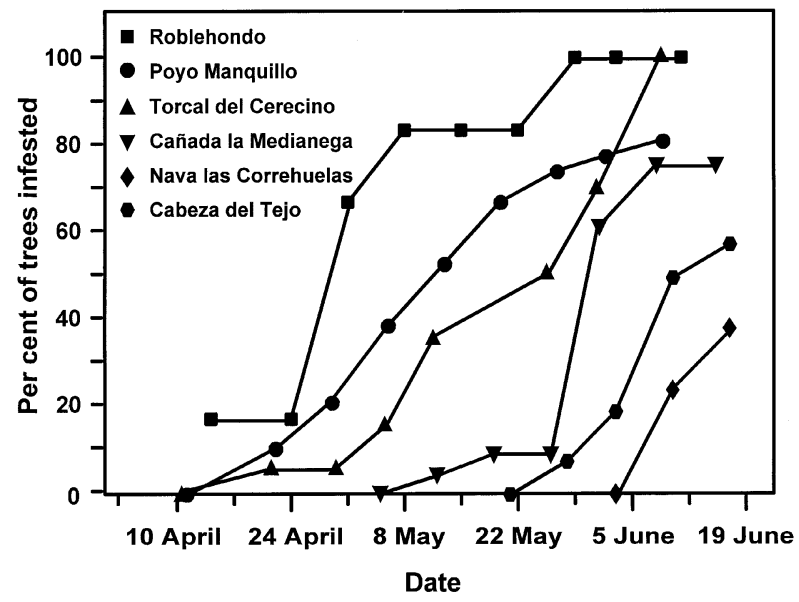

Fig. 5. Phenology of $Y$. mahalebella tent appearance at different locations, showing the percentage of trees at every location where there was at least one $Y$. mahalebella tent during the 10-week study period. Note that all trees presented $Y$. mahalebella tents at the end of the season in only two populations. Populations are ordered by altitude from lowest (Roblehondo) to highest (Cabeza del Tejo) elevation.

lower altitude populations, but they reached the last instar simultaneously at all sites, indicating longer growth periods at lower altitudes.

Adult body marr. Adult body mass was used as an estimate of potential fecundity. As noted above, larvae within the same tent could not be treated as independent samples, so analyses were conducted after computing means for individual tents and using numbers of individuals per tent as a weighting factor (SAS Institute, 1996). Females were significantly heavier (10.33 ! $2.83 \mathrm{mg}, \quad \mathrm{n}=233$ individuals) than males (7.72 【 $1.98 \mathrm{mg}, \mathrm{n}=289)(\mathrm{F}=233.36$, d.f. $=1,332, \mathrm{P}<0.001)$. Mean adult body mass per tent was therefore calculated separately by sex (Table 2 ).

Effects of sex, year, population, and year $\times$ population factors on adult body mass were evaluated. All factors except sex were considered as random effects in a general linear model (Proc GLM; SAS Institute, 1996). The complete model was highly significant $(F=13.24$, d.f. $=11,143, P<0.001)$ and explained $34 \%$ of variance in adult body mass. Neither year $(F=0.11$, d.f. $=1,8.38$, $\mathrm{P}=\mathrm{NS})$ nor population $(\mathrm{F}=0.76$, d.f. $=3,4.12, \mathrm{P}=\mathrm{NS}$ ) showed a significant effect on adult body mass (Table 2 ), but there was a significant year $\times$ population interaction $(F=4.03$, d.f. $=4,143, P<0.01)$ in addition to the sex effect. Separating the data by year, population had a significant effect in both data sets $[F \quad(1994)=3.08$, d.f. $=3,72$, $P<0.03 ; F(1993)=6.47$, d.f. $=4,72, P<0.001]$.

The relationships between adult body mass and both population temperature and elevation were evaluated separately for each study season owing to the significant year $\times$ population interaction in the general linear model (see above). In 1994, there was a positive relationship between adult body mass and mean temperature (Fig.6), with a 
Table 2. Adult body mass of $Y$. mahalebella individuals reared from final-instar larvae collected from different populations. Mean population dry body mass ! SD $(\mathrm{mg})$ is presented separately by sex and year. Population means were calculated based on means per tent and weighted for number of individuals within each tent. Number of tents $\left(n_{t}\right)$ and number of individuals $\left(n_{i}\right)$ are shown. Missing values correspond to absence of individuals.

\begin{tabular}{|c|c|c|c|c|c|c|c|c|c|c|c|c|}
\hline \multirow[b]{3}{*}{ Population } & \multicolumn{6}{|c|}{ Females } & \multicolumn{6}{|c|}{ Males } \\
\hline & \multicolumn{3}{|c|}{1994} & \multicolumn{3}{|c|}{1993} & \multicolumn{3}{|c|}{1994} & \multicolumn{3}{|c|}{1993} \\
\hline & $\mathrm{n}_{\mathrm{t}}$ & $n_{i}$ & $\begin{array}{l}\text { Mean body } \\
\text { mass }\end{array}$ & $\mathrm{n}_{\mathrm{t}}$ & $n_{i}$ & $\begin{array}{l}\text { Mean body } \\
\text { mass }\end{array}$ & $\mathrm{n}_{\mathrm{t}}$ & $n_{i}$ & $\begin{array}{l}\text { Mean body } \\
\text { mass }\end{array}$ & $\mathrm{n}_{\mathrm{t}}$ & $n_{i}$ & $\begin{array}{l}\text { Mean body } \\
\text { mass }\end{array}$ \\
\hline Roblehondo & 0 & 0 & - & 1 & 8 & $11.83 !$ & 1 & 2 & $3.60 !-$ & 2 & 12 & 9.68 ! 3.07 \\
\hline Poyo Manquillo & 18 & 81 & $11.73 \pm 4.07$ & 23 & 70 & 9.64 ! 3.44 & 20 & 108 & $8.42 ! 2.87$ & 27 & 66 & $6.81 ! 2.21$ \\
\hline Torcal del Cerecino & 9 & 27 & 10.68 ! 3.93 & 7 & 26 & 10.48 ! 4.22 & 8 & 20 & $7.03 ! 1.88$ & 9 & 37 & $7.83 ! 2.38$ \\
\hline Cañada la Medianega & 3 & 11 & $10.60 】 1.93$ & 2 & 3 & $9.98 ! 4.44$ & 6 & 14 & $7.36 ! 2.34$ & 3 & 9 & 6.84 ! 1.34 \\
\hline Nava las Correhuelas & 3 & 9 & 10.12 】 1.78 & 0 & 0 & - & 3 & 9 & $7.80 ! 1.31$ & 0 & 0 & - \\
\hline Cabeza del Tejo & 3 & 13 & $8.83 ! 6.34$ & 1 & 3 & 6.30 !- & 3 & 9 & $7.29 ! 2.10$ & 1 & 3 & 3.60 !- \\
\hline
\end{tabular}

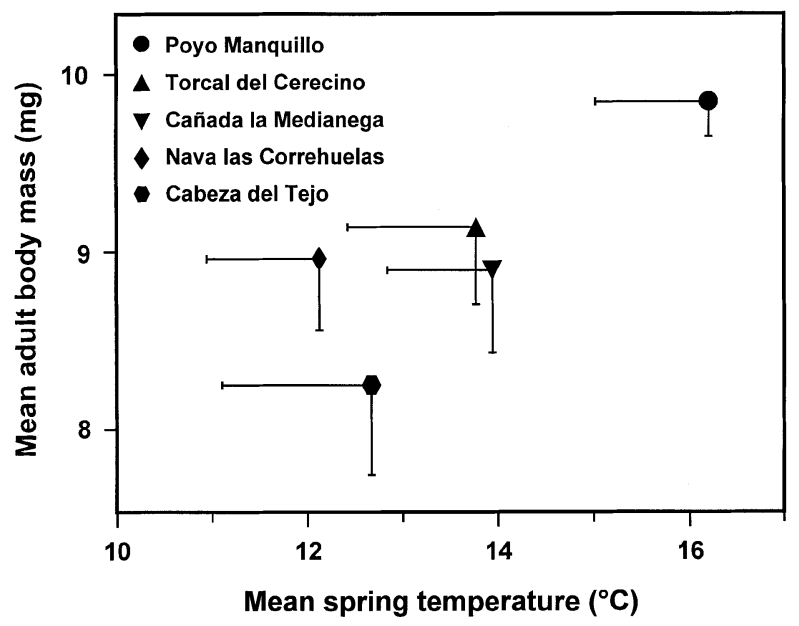

Fig. 6. Relationship between mean adult $Y$. mahalebella body mass and mean temperature recorded at different populations during the larval development period. Symbols represent mean values, and bars $=-$ SEM. Populations are ordered by altitude from lowest (Poyo Manquillo) to highest (Cabeza del Tejo) elevation.

significant steady increase of adult body mass at lower altitudes (isotonic regression $E^{2}=0.12, n=3, P<0.001$ for females; $E^{2}=0.08, n=3, P<0.001$ for males). A similar result was found for 1993 data where only four populations could be used due to reduced sample sizes $\left(E^{2}=0.08, n=4, P<0.03\right.$ for females; $E^{2}=0.19, n=4, P<0.001$ for males).

Herbivore mortality. Two different aspects were considered: larval disappearance during the growing season and parasitism. The mean number of caterpillars per tent was significantly lower at the end of the growing season than at the beginning $(\mathrm{t}=7.9, \mathrm{n}=47, \mathrm{P}<0.001$; Table 3 ). Initial mean number in different populations varied between 19 and 24 caterpillars per tent, and did not differ significantly among populations
( $F=1.17$, d.f. $=3,43, P=N S$ ), however the final numbers differed significantly among populations $(F=9.39$, d.f. $=3,43$, $\mathrm{P}<0.001$; Table 3 ). The percentage of lort larvae during the growing period was also significantly different among populations $(F=8.77$, d.f. $=3,43, P<0.001)$, with greater losses recorded in higher altitude populations (Table 3 ), however it was not possible to evaluate the effect of dispersal in larval disappearance.

Differences in parasitism rates among populations and consistency between years were measured using data for the three populations with adequate sample sizes in both study years (Poyo Manquillo, Torcal del Cerecino, and Cañada la Medianega; Table 4). Differences among populations were statistically significant (generalised logits model: $z^{2}=11.06$, d.f. $=4, P<0.03$ ), with the parasitism rate lowest at Poyo Manquillo site. The population $\times$ year interaction was also significant $\left(z^{2}=33.86\right.$, d.f. $\left.=4, P<0.001\right)$, indicating that there were differences among populations in larval performance between years.

\section{Discussion}

The incidence of herbivores on plants is usually estimated in the literature as either plant defoliation or herbivore abundance, but only rarely have both kinds of measurements been considered simultaneously (see Alonso \& Herrera, 1996). The tight relationship found here between tent length and the number of consumed leaves within it, along with the experimental evidence that tent length was highly dependent of the number of larvae spinning the tent, served to demonstrate that the length of $Y$. mahalebella tents may be used as a reliable indirect estimate of both defoliation and herbivore abundance in this system.

Estimated abundance of $Y$. mahalebella larvae was correlated inversely with site altitude over 2 successive years, a pattern supported by casual observations over many years (C. M. Herrera, pers. comm.), indicating that P. mahaleb populations above $1600 \mathrm{~m}$ never receive massive defoliations, 
Table 3. Caterpillar disappearance during the 1994 growing season. $n_{i}$ is the initial estimated number of caterpillars within a tent, $n_{f}$ is the number of caterpillars collected at the end of the growing season. Per cent loss was calculated from the difference between $n_{i}$ and $n_{f}$ in collected tents. Different letters in the same column indicate statistically-significant differences (Student-Newman-Keuls test, $P<0.03$ ).

\begin{tabular}{lllll}
\hline Population & Number of tents & Mean $\mathrm{n}_{\mathrm{i}}$ & Mean $\mathrm{n}_{\mathrm{f}}$ & Mean percentage loss \\
\hline Poyo Manquillo & 17 & $24.2 ! 10.0^{\mathrm{a}}$ & $14.6 ! 7.4^{\mathrm{a}}$ & $38.2 ! 26.8^{\mathrm{a}}$ \\
Torcal del Cerecino & 10 & $18.2 ! 6.6^{\mathrm{a}}$ & $13.6 ! 7.2^{\mathrm{a}}$ & $26.9^{\mathrm{a}} 17.9^{\mathrm{a}}$ \\
Cañada la Medianega & 12 & $19.3 ! 12.2^{\mathrm{a}}$ & $3.3 ! 2.7^{\mathrm{b}}$ & $73.0 ! 26.8^{\mathrm{b}}$ \\
Cabeza del Tejo & 8 & $18.6 ! 6.9^{\mathrm{a}}$ & $6.3 ! 6.1^{\mathrm{b}}$ & $64.6 ! 27.7^{\mathrm{b}}$ \\
\hline
\end{tabular}

Table 4. Growth result of rearing final-instar larvae collected from different populations. $n_{t}$ is the number of collected tents and $n_{c}$ the number of collected caterpillars. Mean percentages of adults $(A)$, parasitised $(P)$, and dead $(R)$ caterpillars were calculated based on individual tent data.

\begin{tabular}{|c|c|c|c|c|c|c|c|c|c|c|}
\hline \multirow[b]{2}{*}{ Population } & \multicolumn{5}{|c|}{1994} & \multicolumn{5}{|c|}{1993} \\
\hline & $\mathrm{n}_{\mathrm{t}}$ & $\mathrm{n}_{\mathrm{c}}$ & A (\%) & $\mathrm{P}(\%)$ & $\mathrm{R}(\%)$ & $n_{t}$ & $\mathrm{n}_{\mathrm{c}}$ & A (\%) & $\mathrm{P}(\%)$ & R (\%) \\
\hline Roblehondo & 2 & 7 & 23 & 46 & 29 & 4 & 43 & 33 & 19 & 23 \\
\hline Poyo Manquillo & 17 & 249 & 48 & 27 & 23 & 37 & 283 & 48 & 13 & 37 \\
\hline Torcal del Cerecino & 10 & 136 & 33 & 30 & 33 & 9 & 134 & 34 & 12 & 34 \\
\hline Cañada la Medianega & 12 & 40 & 28 & 26 & 46 & 3 & 26 & 42 & 23 & 33 \\
\hline Cabeza del Tejo & 8 & 32 & 31 & 37 & 32 & 1 & 6 & 100 & 0 & 0 \\
\hline Mean & & & $33.3^{*}$ & $30^{*}$ & $34.3^{\star}$ & & & $30 \dagger$ & $17 \dagger$ & $33 \dagger$ \\
\hline
\end{tabular}

* Roblehondo excluded.

† Cabeza del Tejo excluded.

but that these are more frequent below $1400 \mathrm{~m}$. Yponomeuta mahalebella was more abundant at lower elevations, where $P$. mahaleb populations were less well represented (Fig. 2), and was uncommon at the middle and high elevations, where the largest P. mahaleb populations were present (Fig. 2). This suggests that there was some factor(s) affecting the species distributions differentially. A species such as P. mahaleb, at the southern limit of its distribution, may be less stressed and therefore more abundant at higher elevations, where abiotic conditions are more similar to those recorded at more northerly latitudes.

Factors determining the elevational pattern of $\mathrm{Y}$. mahalebella abundance were less evident. Many factors can affect insect herbivore performance along an elevational gradient, including plant phenology (Hodkinson, 1997), plant secondary compounds (Louda \& Rodman, 1983; Koptur, 1983), leaf traits (Kudo, 1996), and abundance of natural enemies (Koptur, 1983). In addition, variation in abiotic conditions related to elevation can similarly affect larval development and abundance. Finally, both biotic and abiotic factors may also vary among sites at similar elevations (Sork et al., 1993). The highly significant correlation found between herbivore abundance and site temperature (Fig. 4) suggests that temperature influences herbivore abundance at different altitudes, probably through differences in degree-day accumulation (Whittaker \& Tribe, 1996; Hodkinson, 1997; Ruohomäki et al., 1997 and references therein). Furthermore, differences in temperature among sites may be amplified by tent structure, because the temperature within tents is related to sun exposure (Alonso, 1997a), and the warmer sites also have longer growing periods. Finally, adult moths at lower elevations were heavier (Fig. 6), in accord with the model for spatial heterogeneity proposed by Sibly and Atkinson (1994) in which 'the optimal plastic strategy is larger adult body size....in warmer habitats'. As body size is usually linked to fecundity in Yponomeuta (Kooi et al., 1989; Leather \& Mackenzie, 1994), individuals at lower elevations probably have higher fecundity, which contributes to their higher abundance.

Losses of $Y$. mahalebella larvae during development were also fewer at the lower sites (Table 3). Climate unpredictability, plant phenology, and natural enemies could not apparently predict the observed pattern of mortality. Myers (1981) suggested that larvae commencing growth late in spring will tend to have lower mortality because climate variability is less than in early spring, however $Y$. mahalebella larval disappearance was highest in the upper populations, which began to grow later (Fig. 3). More detailed studies are needed to evaluate whether small differences in synchrony between leaf flush and the start of larval activity (Aide \& Londoño, 1989) explain differences in disappearance rates, although on the coarse scale studied, phenology does not appear to explain differences in Y. mahalebella abundance. Tent appearance was delayed by approximately 2 weeks at higher elevation sites (Fig. 3), but because the host trees also flushed leaves later, interspecific synchronisation should not be affected unduly, especially because external folivores such as $\mathrm{Y}$. mahalebella larvae are unlikely to be constrained by a lack of suitable food (e.g. Hodkinson \& Bird, 1998). 
Both parasitisation and predation rates also fail to explain larval disappearance during development. Toxic compounds contained in Y. mahalebella larvae (Fung \& Herrebout, 1987; Fung, 1988), combined with gregariousness (SillénTullberg \& Leimar, 1988; Gamberale \& Tullberg, 1996) and protection within tents all serve as predator deterrents. In addition, it might be expected that mortality would be higher where larval growing periods were longer, giving greater opportunity for predator attack (Evans, 1982; but see Benrey \& Denno, 1997), but the observed pattern was just the opposite. Finally, parasitoids were not expected to affect mortality during the early developmental stages, because the main parasitoid species, such as Ageniarpir fursisollir Dalman and Diadegma sp., emerge from finalinstar larvae (see Kuhlman, 1993 and references therein). Moreover, parasitism rates recorded from final-instar larvae were higher in the Poyo Manquillo population where the highest herbivore abundances were recorded. Otherwise, neither differences in plant size nor the mineral or physical properties of $\mathrm{P}$. mahaleb leaves were correlated significantly with recorded herbivore abundance in the study populations (Alonso, 1997b).

The observed elevational pattern of $Y$. mahalebella abundance therefore appears to be related mainly to variation in temperature affecting fecundity. The relationship between temperature and larval mortality remains unknown, but biotic factors did not explain the lower mortality found at the lower elevation sites. A detailed study of thermal requirements of $\mathrm{Y}$. mahalebella larvae will contribute to elucidating whether temperature can also be related to larval mortality. Nevertheless, these results suggest that the magnitude of herbivore pressure can be modified by environmental conditions within a geographical range (Thompson, 1994).

\section{Acknowledgements}

I am particularly indebted to Carlos M. Herrera for teaching, encouragement and valuable advice. He, José M. Gómez, Erkki Haukioja, Ian D. Hodkinson, Simon R. Leather, Lauri Oksanen and two anonymous reviewers made useful comments on earlier versions of this manuscript. Manolo Carrión, Alicia Prieto, and Rocío Requerey assisted with sampling and processing data. The Agencia de Medio Ambiente supported this work in Cazorla, and Spanish DGICYT and Ministerio de Educación y Ciencia funded it through grant PB91-0114, and a predoctoral fellowship. While writing the paper I was supported by a European Commission-TMR fellowship.

\section{Reterences}

Aide, T.M. \& Londoño, E.C. (1989) The effects of rapid leaf expansion on the growth and survivorship of a lepidopteran herbivore. Oikor, $55,66-70$.

Alonso, C. (1997a) Choosing a place to grow. Importance of withinplant abiotic microenvironment for Yponomeuta mahalebella. Entomologia experimentalir et applisata, 83, 171-180.
Alonso, C. (1997b) Variasioner en lar relasioner planta-inrestor Btófagor: efestor de fastorer biótisor y abiótisor. PhD thesis, University of Seville, Spain.

Alonso, C. \& Herrera, C.M. (1996) Variation in herbivory within and among plants of Daphne laureola (Thymelaeaceae): correlation with plant size and architecture. Journal of Esology, 84, 493-302.

Begon, M., Harper, J.L. \& Townsend, C.R. (1996) Esology: Individualr Populationr and Communitier, 3rd edn. Blackwell, Oxford.

Benrey, B. \& Denno, R.F. (1997) The slow-growth-high-mortality hypothesis: a test using the cabbage butterfly. Esology, 78, 987999.

Dijkerman, H.J., Groot, J.M.B. \& Herrebout, W.M. (1986) The parasitoids of the genus Yponomeuta Latreille (Lepidoptera Yponomeutidae) in the Netherlands. Prossedingr of Kononklijke Netherlandre Akademie Van Wetenrshappen C, 84, 379-398.

Dudt, J.F. \& Shure, D.J. (1994) The influence of light and nutrients on foliar phenolics and insect herbivory. Esology, 75, 86-98.

Evans, E.W. (1982) Influence of weather on predator/prey relations: stinkbugs and tent caterpillars. New York Entomologisal Sosiety, 90, 241-246.

Fung, S.Y. (1988) Butenolides in parasitoids of small ermine moths, Yponomeuta spp. (Lepidoptera: Yponomeutidae). Proseedingr of Koninklijke Netherlandre Akademie Van Wetenrshappen C, 91, 363-367.

Fung, S.Y. \& Herrebout, W.M. (1987) Coumarins in Prunur mahaleb and its herbivore the small ermine moth Yponomeuta mahalebellur. Journal of Chemisal Esology, 13, 2041-2047.

Gaines, S.D. \& Rice, W.R. (1990) Analysis of biological data when there are ordered expectations. The Amerisan Naturalirt, 135, 310317.

Gamberale, G. \& Tullberg, B.S. (1996) Evidence for a more effective signal in aggregated aposematic prey. Animal Behaviour, 52, 397601.

Gaston, K.J., Blackburn, T.M. \& Spicer, J.I. (1998) Rapoport's rule: time for an epitaph? Trendr in Esology and Evolution, 13, 70-74.

Herrera, C.M. (1993a) Floral biology, microclimate and pollination by ectothermic bees in an early-blooming herb. Esology, 76, 218-228.

Herrera, C.M. (1993b) Microclimate and individual variation in pollinators: flowering plants are more than their flowers. Esology, 76, 1316-1324.

Hill, J.K. \& Hodkinson, I.D. (1992) Effects of temperature on phenological synchrony and altitudinal distribution of jumping plant lice (Hemiptera: Psylloidea) on dwarf willow (Salix lapponum) in Norway. Esologisal Entomology, 20, 237-244.

Hodkinson, I.D. (1997) Progressive restriction of host plant exploitation along a climatic gradient: the willow psyllid Casoprylla groenlandisa in Greenland. Esologisal Entomology, 22, 47-34.

Hodkinson, I.D. \& Bird, J. (1998) Host-specific insect herbivores as sensors of climate change in Arctic and Alpine environments. Arstis and Alpine Rerearsh, 30, 78-83.

Janzen, D.H. (1983) A host plant is more than its chemistry. Illinoir Natural Hirtory Survey Bulletin, 33, 141-174.

Kooi, R.E. (1990) Hort-plant relestion and larval food-asseptanse by rmall ermine mothr. PhD thesis, University of Leiden. Studier in Yponomeuta, 9. ICG Printing, Dordrecht, The Netherlands.

Kooi, R.E., Herrebout, W.M. \& van de Water, T.P.M. (1989) Observations on pupal and imaginal weights of small ermine moths (Lepidoptera: Yponomeuta). Proseedingr of the Koninklijke Nederlandre Akademie Van Wetenrshappen C, 92, 81-88.

Koptur, S. (1983) Alternative defenses against herbivores in Inga (Fabaceae: Mimosidae) over an elevational gradient. Esology, 66, 1639-1630. 
Kudo, G. (1996) Intraspecific variation of leaf traits in several deciduous species in relation to length of growing season. Esorsiense, 3, 483-489.

Kuhlman, U. (1993) Impast of inrest predatorr and pararitoidr on populationr of the apple ermine moth, Yponomeuta malinellus, (Lepidoptera: Yponomeutidae). PhD thesis, International Institute of Biological Control, Delémont, Switzerland.

Leather, S.R. \& Mackenzie, G.A. (1994) Factors affecting the population development of the bird cherry ermine moth, Yponomeuta evonymella (L.). The Entomologirt, 113, 86-103.

Louda, S.M. \& Rodman, J.E. (1983) Ecological patterns in the glucosinolate content of a native mustard, Cardamine sordifolia, in the Rocky Mountains. Journal of Chemisal Esology, 9, 397-422.

Louda, S.M. \& Rodman, J.E. (1996) Insect herbivory as a major factor in the shade distribution of a native crucifer (Cardamine sordifolia A. Gray, bittercress). Journal of Esology, 84, 229-237.

McCoy, E.D. (1990) The distribution of insects along elevational gradients. Oikor, 58, 313-322.

Myers, J.H. (1981) Interactions between western tent caterpillars and wild rose: a test of some general plant herbivore hypotheses. Journal of Animal Esology, 50, 11-23.

Rousseeuw, P.J. \& Leroy, A.M. (1987) Roburt Regrerrion and Outlier Detestion. Wiley-Interscience, New York.

Ruohomäki, K., Virtanen, T., Kaitaniemi, P. \& Tammaru, T. (1997) Old mountain birches at high altitudes are prone to outbreaks of Epirrita autumnata (Lepidoptera: Geometridae). Environmental Entomology, 26, 1096-1104.
SAS Institute (1996) SAS/STAT Software: Changer and Enhansementr through Releare 6.II. SAS Institute, Cary, North Carolina.

Sibly, R.M. \& Atkinson, D. (1994) How rearing temperature affects optimal adult size in ectotherms. Funstional Esology, 8, 486-493.

Sillén-Tullberg, B. \& Leimar, O. (1988) The evolution of gregariousness in distasteful insects as a defense against predators. The Amerisan Naturalirt, 132, 723-734.

Sork, V., Stowe, K.A. \& Hochwender, C. (1993) Evidence for local adaptation in closely adjacent populations of northern red oak (Quersur rubra L.) expressed as resistance to leaf herbivores. The Amerisan Naturalirt, 142, 928-936.

Stevens, G.C. (1992) The elevational gradient in altitude range: an extension of the Rapoport's latitudinal rule of altitude. The Amerisan Naturalirt, 140, 893-911.

Strathdee, A.T. \& Bale, J.S. (1998) Life on the edge: insect ecology in arctic environments. Annual Review of Entomology, 43, 83-106.

Thompson, J.N. (1994) The Co-evolutionary Proserr. University of Chicago Press, Chicago, Illinois.

Van Driesche, R.G., Bellows, T.S., Elkinton, J.S., Gould, J.R. \& Ferro, D.N. (1991) The meaning of percentage parasitism revisited: solutions to the problem of accurately estimating total losses from parasitism. Environmental Entomology, 20, 1-7.

Whittaker, J.B. \& Tribe, N.P. (1996) An altitudinal transect as an indicator of responses of spittlebug (Auchenorrhyncha: Cercopidae) to climate change. European Journal of Entomology, 93, 319-324. 